\title{
Evidence for Enhanced Dissipation of Chlorpyrifos in an Agricultural Soil Inoculated with Serratia Rubidaea Strain ABS 10
}

\section{Asma Ben Salem ( $\square$ bensalemasma@yahoo.fr)}

National Institute of Applied Sciences and Technology: Institut National des Sciences Appliquees et de Technologie

\section{Hanene Chaabane}

INAT: Institut National Agronomique de Tunis

\section{Tesnime Ghazouani}

INSAT: Institut National des Sciences Appliquees et de Technologie

\section{Pierluigi Caboni}

University of Cagliari

Valentina Coroneo

University of Cagliari

\section{Marion Devers}

AgroSup Dijon

Jérémie Béguet

AgroSup Dijon

Fabrice Martin Laurent

AgroSup Dijon

\section{Sami Fattouch}

INSAT: Institut National des Sciences Appliquees et de Technologie

\section{Research Article}

Keywords: Chlorpyrifos, mineralization, dissipation, biosorption, Serratia rubidaea strain ABS 10 (S10), soil

Posted Date: April 20th, 2021

DOI: https://doi.org/10.21203/rs.3.rs-355675/v1

License: (c) (i) This work is licensed under a Creative Commons Attribution 4.0 International License.

Read Full License 
Version of Record: A version of this preprint was published at Environmental Science and Pollution Research on January 6th, 2022. See the published version at https://doi.org/10.1007/s11356-021-177720 . 


\section{Abstract}

Important mineralization of ${ }^{14} \mathrm{C}$-chlorpyrifos was found in a Tunisian soil exposed repeatedly to this insecticide. A bacterial strain able to grow in minimal salt medium (MSM) supplemented with $25 \mathrm{mg} \mathrm{L}^{-1}$ of chlorpyrifos was isolated from this soil. It was characterized as Serratia rubidaea strain $A B S 10$ using morphological and biochemical analyses, as well as $16 \mathrm{~S}$ rRNA sequencing. In liquid culture $S$. rubidaea stain $A B S 10$ was able to almost entirely dissipate chlorpyrifos within 48 hours of incubation. Although, $S$. rubidaea strain $A B S 10$ was able to grow on MSM supplemented with chlorpyrifos and to dissipate it in liquid culture, it was not able to mineralize ${ }^{14} \mathrm{C}$-chlorpyrifos. Therefore, one can conclude that the dissipation capability of this bacteria might be attributed to its capacity to adsorb CHL. In both non-sterile and sterile soil inoculated with $S$. rubidaea strain $A B S 10$, chlorpyrifos was more rapidly dissipated than in respective controls.

\section{Introduction}

After the ban of organochlorines (such as DDT, dieldrin or heptachor) and carbamates (such as carbofuran), organophosphorus insecticides (OPs) have been extensively used in agriculture as a substitute insecticides because of their high efficiency and their supposed relatively low persistence and low effect on the environment (Yang et al. 2005). However, the widespread use of OPs has led to severe environmental issues because these compounds are often transported away from the sites where they have been applied. For instance, OPs may enter aquatic environments via soil percolation, air drift or surface runoff (Liang et al. 2011). Numerous reports indicate that OPs are toxic to humans causing metabolic disorders and neuropathy in response to both acute and chronic exposure (lyer and Makris, 2010). Among OPs, chlorpyriphos ( $\mathrm{CHL}$ ) with a broad-spectrum activity is one of the most frequently used. $\mathrm{CHL}$ has relatively low water solubility $\left(2 \mathrm{mg} \cdot \mathrm{L}^{-1}\right)$ and is spontaneously hydrolyzed to $3,5,6-$ trichloro-2-pyridinol(TCP) (Li et al. 2008). Although being applied on crop cover, a large proportion of this insecticide reaches the soil, where both abiotic (i.e. sorption chemical degradation) and biotic (biodegradation) processes control the fate and the activity of this compound. Particularly, the half-life (DT ${ }_{50}$ ) of chlorpyrifos in soil is usually between 10 and 120 days, depending on the soil type, climate and other environmental conditions such as composition of microbial communities (Abraham and Silambarasan, 2016). Indeed, microbial activity has been deemed the most influential and significant cause of the OPs pesticides removal (Li et al. 2005). The ability of microorganisms to degrade OPs is viewed as the primary means of removing these agrochemicals from soils (Cycon et al. 2013). A range of species of bacteria capable of degrading OPs especially $\mathrm{CHL}$ by co-metabolism or by using pesticides as a source of carbon and phosphorous (Cycon et al. 2013) has been reported by several researchers, Enterobacter stain B-14, Stenotrophomonas sp. Strain YC-, Sphingomonas sp. Strain, Dsp-2, Paracoccus sp. strain TRP, Bacillus pumilus strain C2A1, Cupriavidus sp. DT-1, Alcaligenes faecalis, Flavobacterium sp, Klebsiella sp, Serratia sp, Pseudomonas sp (Silambarasan and Abraham 2013, Chisti et al. 2013). Furthermore, it has been observed that repeated application of OPs lead to the enhancement of their biodegradation in reason of the selection of degrading microbial populations (Singh et al. 2003). More 
investigation on microbial degradation of the OPs are required in order to not only understand processes involved in their degradation but also to be able to develop bioremediation strategies to clean contaminated soils (Cycon et al. 2013). Indeed, microbe based remediation relying on biosorption, bioaccumulation, biotransformation or biomineralisation processes (Ayangbenro and Babalola 2017), has received an increasing attention as it seems an applicable and cost-effective biotechnology to clean up soils polluted with OPs (Singh et al. 2006; Chen et al. 2011). On the one hand, biotransformation and biomineralization both contribute to the transformation of the pollutant, the last being viewed as the gold standard as it leads to the complete transformation of the pollutant. Moreover, biosorption and bioaccumulation contribute to the stabilization of pollutant in the environmental matrice by forming nonextractable residues that are almost not-transferable to other compartment of the environment. From this point of view, these last two processes are of interest to clean contaminated water by using microbial biomass as a low-cost biobased adsorbent (Khadivinia et al. 2014) or to stabilize pollutant in a given contaminated matrices' in order to avoid further dispersion in the environment.

Hence, the present study aims not only to estimate the adaptation of microbial community of an agricultural soil regularly exposed to $\mathrm{CHL}$ to its enhanced mineralization, but also to isolate and characterize bacterial isolates able to grow on $\mathrm{CHL}$ as sole carbon source. The ability of one bacterial isolate to dissipate $\mathrm{CHL}$ was estimated in liquid culture and in soil microcosms incubated under controlled conditions in the laboratory in order to estimate its interest for bioremediation purposes.

\section{Materials And Methods}

\section{Chemicals and culture medium}

The tested compounds CHL (99.5\% purity) was purchased from Sigma-Aldrich (St. Louis, MO, USA). All other reagents (dimethyl sulfoxide DMSO and dichloromethane) used in this study were of high purity and analytical grade. Organic free water was prepared with a Milli-Q/Milli-Ro system (Millipore Corp., Bedford, MA, USA). Stock solutions of chlorpyrifos were prepared at $5000 \mathrm{mg} \mathrm{L}^{-1}$ in dimethyl sulfoxide (DMSO). For each experiment, $1 \mathrm{~mL}$ of $\mathrm{CHL}$ was added in the medium. For the microbial assays, mineral salt medium (MSM) and Luria-liquid broth (LB) were used. The medium (MSM) contained $20 \mathrm{~mL}$ of $\mathrm{K}_{2} \mathrm{HPO}_{4}, 10 \mathrm{~mL}$ of $\mathrm{MgSO}_{4} 7 \mathrm{H}_{2} \mathrm{O}, 10 \mathrm{~mL}$ of $\mathrm{NaCl}, 1 \mathrm{~mL}$ of $\mathrm{CaCl}_{2}, 2 \mathrm{~g}$ of boric acid, 0,2 $\mathrm{g}$ of ZnSO${ }_{4}, 0,8 \mathrm{~g}$ of CuSO $, 0,25 \mathrm{~g}$ of $\mathrm{NaNO}$, and $0,05 \mathrm{~g}$ of $\mathrm{CO}\left(\mathrm{NO}_{2}\right)_{2}, 1 \mathrm{~mL}$ of $\mathrm{FeSO}_{4} 6 \mathrm{H}_{2} \mathrm{O}$ was added per liter of distilled water. The medium (LB) contained $10 \mathrm{~g}$ of peptone, $5 \mathrm{~g}$ of yeast extract and $10 \mathrm{~g}$ of $\mathrm{NaCl}$ per 1 liter of distilled water $(\mathrm{pH} 7.0)$. After autoclaving $\left(121^{\circ} \mathrm{C}, 20 \mathrm{~min}\right)$ and cooling the medium was supplemented with a suitable $\mathrm{CHL}$ solution prepared as described above.

\section{Sampling}

The soil sample used in this study was collected from field site located in Mornag approximately $20 \mathrm{~km}$ away from Tunis $\left(36^{\circ} 67^{\prime} 70.39 \mathrm{~N}, 10^{\circ} 27^{\prime} 53.78 \mathrm{E}\right)$, Tunisia. The sampling site has been in use for 
intensive agricultural practices since long and this soil has received leachates after application of chlorpyrifos for several years. Soil sample was collected from a depth of $20 \mathrm{~cm}$. Soil was mixed thoroughly and plant debris were removed. Then soil was sieved at $2 \mathrm{~mm}$ and kept at $4^{\circ} \mathrm{C}$ until its use (for less than 3 weeks).

\section{Mineralization of ${ }^{14} \mathrm{C}-\mathrm{CHL}$ in soil microcosms}

The potential of the soil microbial community to mineralize chlorpyriphos $(\mathrm{CHL})$ was evaluated using ${ }^{14} \mathrm{C}$ labelled CHL (Izotop, specific activity $=118 \mu \mathrm{Ci} / \mathrm{mg}$ ) as described by El-Sebai et al. (2007). Four individual replicates of $20 \mathrm{~g}$ soil microcosms were studied. For each replicate $1 \mathrm{~mL}$ of a methanol solution comprising $60 \mathrm{mg} \cdot \mathrm{L}^{-1}$ of ${ }^{14} \mathrm{C}-\mathrm{CHL}$ and $0.068 \mu \mathrm{Ci}$ of ${ }^{14} \mathrm{C}-\mathrm{CHL}$ was applied on an aliquot of $1 \mathrm{~g}$ of dried soil. After evaporation $\mathrm{CHL}$ contaminated soil was thoroughly mixed with the rest of soil. Soil humidity was then adjusted to $40 \%$ of the water holding capacity (WHC) and kept constant all along the 70 days of incubation in the radiorespirometer. ${ }^{14} \mathrm{CO}_{2}$ evolved from ${ }^{14} \mathrm{C}-\mathrm{CHL}$ was quantified by liquid scintillation counting (LS 6500 Multi-Purpose Scintillation Counter, Beckman) using ACSII scintillation fluid (Amersham) (Storck et al. 2017).

\section{Enrichment procedure, isolation and characterization of chlorpyrifos degrading strain}

Preliminary screening experiments were performed to obtain strains that were tolerant to CHL. The study was conducted as described previously by Ben Salem et al. 2016.

Only one soil with three replicates was used in this study. Fresh soil sample was divided in six subsamples of $50 \mathrm{~g}$ dry weight equivalent. Aqueous $\mathrm{CHL}$ solution were prepared at $4.8 \mathrm{~g}^{-1} \mathrm{~L}^{-1}$ (which corresponds to 10 times the recommended dose agronomic purpose) the day of its application starting from Robust ${ }^{\circledR}$ formulated solution. The duration of experiment was two weeks.

Soil samples were incubated at room temperature under laboratory conditions. They were watered every two days to keep soil humidity at $40 \%$ of water holding capacity (WHC). Every two days, they were irrigated with $10 \mathrm{~mL}$ of commercial chlorpyrifos solutions as $10 \mathrm{X}$ concentrated solutions of pesticides to exert a selective pressure favorable to the emergence of degrading bacterial populations. Three samples were not treated with $\mathrm{CHL}$ but with equivalent amount of pure water (control). Two-days after $\mathrm{CHL}$ application, soil was sampled to immediately carry bacterial isolation. Briefly, one g of soil was added to $10 \mathrm{~mL}$ of physiological water ( $\mathrm{NaCl} 9 \%$ ) and serially ten-times diluted. $100 \mu \mathrm{L}$ of $10,10^{-2}$ and $10^{-4}$ dilutions were streaked on PCA plates that were incubated for 16 hours at $37^{\circ} \mathrm{C}$. Each colony growing on the plate was purified using the $Z$ streak technique. 
Primary distinction between all the isolates was based on the size, color and morphology of their colonies on the PCA plates. Bacterial colonies showing different morphologies were selected and further characterized using API 20E (Biomérieux, Lyon, France) following the recommendations of the Bergey's manual of systematic bacteriology (Krieg et al. 1984). In addition, 16 S rRNA amplicon generated by PCR using the $27 f$ and $1492 r$ universal primer pair (Gürtler and Stanisich 1996) from DNA extracted from the bacterial isolate was sequenced as previously described (Devers et al. 2008). 16S rRNA sequence was compared to other sequences available in GenBank database (http: //www. ncbi.nlm.nih.gov/genbank) using the BlastN search analysis (http://www.blast.ncbi.nlm.nih.gov/). Sequence was deposited in the Genbank database (SUB8916609 S10 MW494965).

\section{Bacterial growth kinetics in different liquid media}

To investigate the growth of Serratia rubidaea strain $A B S 10$ with chlorpyrifos, $200 \mu$ l of strain (OD $600=$ 0.8 ) were inoculated into $20 \mathrm{~mL}$ of either MSM or nutrient broth medium added with $\mathrm{CHL}$ at a final concentration of $25 \mathrm{mg} \cdot \mathrm{L}^{-1}$. The culture was incubated at $30 \pm 2^{\circ} \mathrm{C}$ on a rotary shaker at $120 \mathrm{rpm}$. The bacterial growth was regularly monitored for 5 days by measuring the turbidity of the culture using a spectrophotometer at $600 \mathrm{~nm}$.

\section{Inoculum preparation}

A bacterial colony was inoculated in LB medium and grown to reach the exponential phase. It was then collected by centrifugation at $5000 \mathrm{~g}$ for $5 \mathrm{~min}$. The cell pellet was washed twice with $0.9 \%$ of sterile $\mathrm{NaCl}$ and then re-suspended in $\mathrm{NaCl}$ to obtain the bacterial suspension at a concentration of approximately $3.10^{6} \mathrm{CFU} / \mathrm{mL}$. The cell density (OD $600 \mathrm{~nm}$ ) was measured using UV-Visible spectrophotometer (Lu et al. 2013)

\section{Dissipation of chlorpyrifos by $S$. rubidaea strain ABS 10 in aqueous medium}

$\mathrm{CHL}$ dissipation studies were performed in $250 \mathrm{~mL}$ Erlenmeyer flasks containing $100 \mathrm{~mL}$ of sterile MSM supplemented with $\mathrm{CHL}$ at $25 \mathrm{mg} \mathrm{L}^{1}$ and inoculated with $1 \mathrm{~mL}$ of bacterial strain (approximately $3 \times 10^{6}$ cells. $\mathrm{mL}^{-1}$ ). Un-inoculated media comprising with the same concentration of $\mathrm{CHL}$ were used as control. All the samples were incubated at $30 \pm 2^{\circ} \mathrm{C}$ on a rotary shaker at $120 \mathrm{rpm}$ for 5 days. Samples were periodically taken from the culture under aseptically conditions to measure the remaining pesticide concentration the culture medium. 


\section{Dissipation of chlorpyrifos by S.rubidaea strain $A B S 10$ in soil}

To study the dissipation of chlorpyrifos in sterilized (SS) or natural (NS) soil inoculated with $S$.rubidaea strain $A B S 10$ (B) or not S. rubidaea strain $A B S 10$. Briefly, $100 \mathrm{~g}$ of sterilized soil (SS) or natural soil (NS) was placed in a $250 \mathrm{ml}$ Erlenmeyer flask, inoculated or not with $30 \mathrm{ml}$ of a $S$. rubidaea strain $A B S 10$ suspension (B) containing $3 \times 10^{6}$ cells. $\mathrm{mL}^{-1}$ and treated with $\mathrm{CHL}$ at $25 \mathrm{mg} \mathrm{kg}^{-1}$. The amount of carbon, nitrogen and phosphorous were calculated using the relationship C/N/P 100:10:1. The sources of carbon, nitrogen and phosphorous were glucose, $\left(\mathrm{NH}_{4}\right)_{2} \mathrm{SO}_{4}$ and $\mathrm{K}_{2} \mathrm{HPO}_{4}$ respectively (Martin et al. 2007). Sterilized soil not inoculated with $S$. rubidaea strain $A B S 10$ was used to estimate abiotic dissipation of $\mathrm{CHL}$ (Pino et al. 2011). All flasks were incubated in an incubator at $30 \pm 2{ }^{\circ} \mathrm{C}$. Samples were periodically removed aseptically to determine the pesticide concentration. Each treatment was performed in triplicate $\left(n_{\text {tot }}=12\right)$.

\section{Analytical methods}

At regular intervals, 5-10 mL cultures were withdrawn from aqueous medium and centrifuged at $7200 \times$ $\mathrm{g}$ for 10 min to obtain a cell-free medium. CHL was extracted twice from the supernatant with an equal volume of dichloromethane (DCM). Organic layers of DCM were pooled and evaporated at $28 \pm 2{ }^{\circ} \mathrm{C}$. For the analysis of $\mathrm{CHL}$ in soil, $5 \mathrm{~g}$ of soil samples was mixed with $10 \mathrm{ml}$ of dichloromethane. The samples were ultra-sonicated for $30 \mathrm{~min}$ at $30^{\circ} \mathrm{C}$. After that, the mixture was centrifuged for $30 \mathrm{~min}$ on a rotary shaker at $120 \mathrm{rpm}$. Then the samples were allowed to stand until the soil had settled, and the clear supernatant was used to determine the pesticide concentration by GC-MS. Levels of CHL were measured by GC-MS using an Agilent 6850N gas chromatograph (Agilent Technologies, USA), equipped with an Agilent6973 MS detector. A capillary column HP-5MS (30 m, $0.25 \mathrm{~mm}, 0.50 \mathrm{~mm})$ was used while chromatographic separation was achieved with the following method: the GC oven temperature was initially set at $70^{\circ} \mathrm{C}$, for $2 \mathrm{~min}$, and raised to $270^{\circ} \mathrm{C}$ at a rate of $20^{\circ} \mathrm{C} / \mathrm{min}$ and held for $10 \mathrm{~min}$. The injector and detector were set at 250 and $280^{\circ} \mathrm{C}$, respectively. The carrier gas Helium was used as at a constant flow rate of $1 \mathrm{~mL} / \mathrm{min}$. Electron impact (70ev) mass spectra were recorded from 100 to $550 \mathrm{amu}$ (atomic mass unit).

\section{Data analysis}

The four kinetic models proposed by the FOCUS working group on pesticide degradation kinetics (FOCUS, 2006) were used to calculate pesticide dissipation kinetic parameters. The four kinetic models proposed by the FOCUS working group on pesticide degradation kinetics (FOCUS, 2006) were used to calculate pesticide dissipation kinetic parameters: the single first order kinetic model (SFO), and the biphasic models hockey stick (HS), first order multi-compartment model (FOMC) and double first order in parallel model (DFOP). 
Data obtained from the dissipation experiments were fit to the exponential decay model. The first-order model and the $\mathrm{DT}_{50}$ was calculated as follows:

$$
\begin{aligned}
& \mathrm{C}_{\mathrm{t}}=\mathrm{C}_{0} \cdot \mathrm{e}^{-\mathrm{kt}} \\
& \mathrm{t}_{1 / 2}=\mathrm{DT}_{50}=\operatorname{Ln}(2) / \mathrm{k}
\end{aligned}
$$

Where $C_{t}$ is the concentration of pesticide remaining in MSM or soil after $t$ days, $C_{0}$ is the initial concentration of pesticide in MSM or soil. $k$ and $t$ are the rate constant $\left(\mathrm{d}^{-1}\right)$ and degradation time in days respectively (Focus, 2006)

\section{Statistical analysis}

All the experiments were performed in triplicates. The data were statistically analyzed using two-way analysis of variance (ANOVA). When significant differences test $(P \leq 0.05)$ were observed, the means were separated using Graphpad Prism, v7.00.

\section{Results And Discussion}

\section{Mineralization of ${ }^{14} \mathrm{C}-\mathrm{CHL}$ in soil microcosms}

After a ten days lag-phase, the soil microbial community efficiently mineralized ${ }^{14} \mathrm{C}-\mathrm{CHL}$ reaching up to $70 \%$ of mineralization of initial radioactivity applied (Fig. 1). During the exponential phase, the rate of mineralization was $1.3 \%{ }^{14} \mathrm{C}-\mathrm{CO}_{2}$ per day. The mineralization curve had sigmoid shape characteristics from microbial community adapted to enhanced degradation of pesticides. One could hypothesize that in response to the repeated $\mathrm{CHL}$ treatments applied to this arable soil the microbial community adapted to its enhanced biodegradation that provides nutrient and energy sources for the growth $\mathrm{CHL}$-degrading community.

Indeed, the emergence of degrading microorganisms, among which $\mathrm{CHL}$-degraders, has been observed in soils regularly exposed to different pesticides (Singh, 2009). The use of pesticides as nutrient and energy sources provides a selective advantage over other microorganisms (Copley, 2009). Adaptation to enhanced degradation seems to be a common trait to soil microorganisms in response to repeated pesticide treatments (Crouzet et al. 2010; De Andrea et al. 2003; Hussain et al. 2011; Vischetti et al. 2008; Weaver et al. 2007). This is an environmental-friendly functional trait because it decreases the persistence of pesticide residues in the soil as well as their dispersion in the environment and their ecotoxicological impact to non-target organisms and supported ecosystem services (Topp et al. 2004). 


\section{Isolation and characterization of bacterial strain growing on $\mathrm{CHL}$ medium}

In order to isolate bacterial strain able to transform $\mathrm{CHL}$, enrichment cultures on MSM medium added with $\mathrm{CHL}$ were conducted. In total we have been able to isolate four bacterial isolates able to grow on MSM-CHL medium. Among these isolates, only one has the capability to grow on liquid MSM-CHL. This isolate is aerobic, none spore forming, Gram negative, straight rods with rounded ends bacteria producing small circular colonies on the nutrient agar plates. Its freshly grown culture showed positive tests for oxidase, catalase, and exhibited the ability of nitrate reduction (Table 1). Its 16S rRNA gene sequence is 99\% similar to Serratia rubidaea strain NBRC 103169 (Ac n NR_114232), JCM1240 (Ac n NR_024644), and DSM 4480 (Ac $n^{\circ}$ NR_114716). Consequently, we proposed to name it Serratia rubidaea strain ABS S10 (S10). 
Table 1

Morphological and biochemical characteristics of bacterial strain Serratia rubidaea strain ABS 10 (+ active; - inactive)

\begin{tabular}{|ll|}
\hline Characteristics & Serratia rubidaea strain ABS 10 \\
\hline Colony morphology & small circular colonies on the nutrient agar plates \\
Gram strain & - \\
Motility & + \\
Indole test & - \\
\hline Methyl red & - \\
\hline Voges-Proskauer & + \\
\hline Citrate utilisation & + \\
\hline Catalase & + \\
\hline Oxidase & - \\
\hline Urease & - \\
\hline Nitrate reduction & + \\
\hline $\mathrm{H}_{2} S$ production & - \\
\hline Gelatin liquefaction & + \\
\hline Glucose & + \\
\hline Sucrose & + \\
\hline Lactose & - \\
\hline Arabinose & - \\
\hline Sorbitol & + \\
\hline Mannitol & + \\
\hline Rhamnose & + \\
\hline
\end{tabular}

Moreover, the growth of S10 was monitored in MSM-CHL and NB-CHL media (containing $25 \mathrm{mg}^{-\mathrm{L}^{-1}}$ of $\mathrm{CHL}$ ) (Fig. 2). As expected S10 was unable to grow on MSM not supplemented with CHL. Contrariwise it slightly grew on MSM supplemented with $\mathrm{CHL}$ as sole carbon source reaching $0.06 \pm 2$ a.u. after seventytwo hours. Likewise, the growth of $S$. rubidaea strain ABS 10 was promoted by approximately a factor two in the NB medium complemented with $\mathrm{CHL}$ as compared to the control. In both cases, a sharp increase in growth was observed up to one day and the maximum growth was obtained after three days. These results suggest that $\mathrm{S} 10$ can use $\mathrm{CHL}$ for its growth. However, on mineral salt medium the culture poorly grew suggesting some metabolic limitations. This was confirmed by the fact that $S$. rubidaea 
strain ABS 10 was unable to mineralize ${ }^{14} \mathrm{C}-\mathrm{CHL}$ labelled on the pyridine ring, suggesting that this strain was not able to get access to $C$ of the ring. Our observation is in accordance with earlier studies reporting that a range of bacterial isolates such as, Serratia $s p$ (Xu et al. 2007) Sphingobacterium sp, Alcaligens sp (Abraham et al. 2013) Serratia marcescens (Cycon et al. 2013) Pseudomonas kilonensi (Khalid et al. 2016) able to grow in minimum salt medium supplemented with $\mathrm{CHL}$ as sole carbon source. In addition, the supplementation of MSM-CHL medium with simple $\mathrm{C}$ source such as glucose or sucrose or more complex one such as NB was shown to promote the growth of Pseudomonas kilonensi SRK1 suggesting that easily degradable $\mathrm{C}$ source can fuel $\mathrm{CHL}$ degradation (Khalid et al. 2016). In fact, $\mathrm{CHL}$ has reported to be degraded by bacteria co-metabolically that required additional carbon sources (Singh et al. 2006; Xu et al. 2008 Abraham et al. 2013).

Among Serratia species, S. marcescens was shown to be able to use CHL concentration of $50 \mathrm{mg} \cdot \mathrm{L}^{-1}$ as the only carbon source when grown in MSM (Abraham et al. 2013). Furthermore, others species of Serratia were characterized for their high potential to grow in MSM supplemented with another OPs such as diazinon (Abo-Amer 2011).

\section{Dissipation of $\mathrm{CHL}$ by strain S. rubidaea strain ABS 10 in liquid medium}

The dissipation of CHL by S10 culture was assessed in resting cell experiment (Fig. 3). S10 rapidly dissipated CHL with a rate of approximately $2.03 \mathrm{mg} \mathrm{CHL}$ per day. Within 24 hours, $92 \%$ of $\mathrm{CHL}$ initially added was dissipated by S. rubidaea strain ABS 10 while only $20 \%$ of dissipation was observed in the control, which consists of sterile medium not inoculated with this strain. It is noteworthy that as expected $\mathrm{CHL}$ was also dissipated in the control but at slower rate than in the S. rubidaea strain ABS 10 culture, and after 5 days of incubation $50 \%$ of the initial dose of chlorpyrifos remains. CHL half-life in S10 culture was significantly lower than in the control (1.15 vs 4.95 days, respectively) thereby confirming its ability to dissipate it. Keeping in mind that $S$. rubidaea strain ABS 10 was unable to mineralize ${ }^{14} \mathrm{C}-\mathrm{CHL}$, one could suggest that the rapid CHL dissipation in S. rubidaea strain ABS 10 culture was not due to its mineralization but probably to its adsorption on bacterial cells as it was previously shown for the herbicide 2,4-D (Benoit et al. 1998) or the insecticide chlordecone (Merlin et al. 2014) on fungal biomass. Indeed, giving the fact that $\mathrm{CHL}$ is highly hydrophobic, it has strong affinity to phospholipid bilayer constituting microbial cell membrane on which it can sorb. $\mathrm{CHL}$ was previously reported to be hydrolyzed co-metabolically by microorganisms (Chisti, et al. 2013) fueled by other $\mathrm{C}$ sources than CHL which, in this case, does not constitute a source of $C$ or energy to sustain its growth (Singh et al. 2006; Xu et al. 2008; Abraham et al. 2013).

\section{Dissipation of $\mathrm{CHL}$ in soil}


Dissipation of CHL was monitored in sterile- (Fig. 4, panels A) and native-soil (Fig. 4, panels B) microcosms inoculated with $\mathrm{S10}$ or not (control). Similar CHL dissipation kinetics were observed in noninoculated sterile and native soils. These two kinetics of dissipation were biphasic and $\mathrm{CHL} \mathrm{DT}_{50}$ was estimated to 2.1 days for both treatments. Despite the fact that the native soil microflora is able to mineralize this insecticides ( $\mathrm{CHL}$ ), no differences in the dissipation kinetics observed in sterile- and native-soils treated $\mathrm{CHL}$ ). This apparent discrepancy is explained by the fact that the dissipation was monitored only during a 6 days period of time during which mineralization of ${ }^{14} \mathrm{C}-\mathrm{CHL}$ is very low (Fig. 1). Therefore over this short period of time $\mathrm{CHL}$ mineralization does not contribute to observed dissipation which is most likely mainly governed by abiotic processes such as sorption on soil components.

The inoculation of $S 10$ in the sterile and native soils resulted in a marked increase in the rate of $\mathrm{CHL}$ dissipation as compared to their respective control (Fig. 4). In the inoculated native and sterile soils the $\mathrm{CHL} \mathrm{DT}_{50}$ were estimated to 1.1 days and 1.4 days, respectively (Table 2). Having in mind that the dissipation of $\mathrm{CHL}$ in $\mathrm{S} 10$ culture was controlled by its sorption to bacterial cells, the improvement of the dissipation of $\mathrm{CHL}$ observed in inoculated soils might be attributed to its biosorption on microbial cells. This hypothesis is supported by the hydrophobic nature of $\mathrm{CHL}$ which provides to it a strong lipophilicity compatible with the development of strong interaction with the cell membrane of microorganisms (Angelova and Schumauder 1999).

Table 2

Kinetic data for the dissipation of $\mathrm{CHL}$ in aqueous medium (Minimum Salt Medium MSM) and soils (SS: sterile soil and NS: native soil) by Serratia rubidaea strain ABS 10 (B). Controls not inoculated with Serratia rubideae strain ABS 10 were included. Data of dissipation kinetics were fitted to a decay model, where $\mathrm{K}$ is the rate of dissipation (day-1) and DT50 is the time required to reach $50 \%$ of the initial pesticide dose.

\begin{tabular}{|llllll|}
\hline Medium & Treatment & Equation & $\mathbf{R}^{2}$ & $\mathbf{k}\left(\right.$ day $\left.^{-1}\right)$ & DT50 (days) \\
\hline MSM & Control & $\mathrm{C}_{\mathrm{t}}=27.3 \mathrm{e}^{-0,1 x}$ & 0.9 & 0.1 & 4.5 \\
\hline MSM & $\mathrm{B}$ & $\mathrm{Ct}=9.8 \mathrm{e}^{-0,6 x}$ & 0.8 & 0.6 & 1.1 \\
\hline NS & Control & $\mathrm{C}_{\mathrm{t}}=39.7 \mathrm{e}^{-0,3 \mathrm{x}}$ & 0.9 & 0.3 & 2.1 \\
\hline SS & $\mathrm{B}$ & $\mathrm{C}_{\mathrm{t}}=7,3 \mathrm{e}^{-0,6 \mathrm{x}}$ & 0.7 & 0.6 & 1 \\
\hline SS & Control & $\mathrm{Ct}=39,4 \mathrm{e}^{-0,3 x}$ & 0.9 & 0.3 & 2.1 \\
\hline
\end{tabular}

In this short-term experiment, the dissipation of $\mathrm{CHL}$ was mainly governed by abiotic processes which combined the sorption to soil components and the biosorption to $S$. rubidaea strain ABS 10 cells $\left(3.10^{6}\right.$ CFU. $\mathrm{mL}^{-1}$ ) 
Several microorganisms including bacteria, fungi and algae have been already reported as effective biosorbents for removal of dyes, metal and even pesticides due to its low cost, non-toxic approach regeneration capability and high efficiency for pollutant uptake (Pathak and Dikshit, 2011). Particularly, bacteria have been used as biosorbents owing to their ubiquity, size, and ability to grow under controlled conditions and resilience to an extensive range of environmental conditions (Ayangbenro and Babalola 2017). Various heavy metals have been tested on bacteria species such as Pseudomonas, Enterobacter, Bacillus and Micrococcus species. Their excellent sorption capacity is due to their high surface-to-volume ratios and their numerous potential active chemosorption sites, such as the teichoic acid on the cell wall (Mosa et al. 2016). Likewise, Zakeri et al. 2010 reported also that Serratia sp was an efficient radium biosorbent and might be appropriate candidate for designing biosorption remediation system.

\section{Conclusion}

This study showed that in response to long term exposure to $\mathrm{CHL}$, the soil microflora adapted to its enhanced mineralization. S.rubidaea strain ABS 10 a bacterial strain able to grow on mineral salt medium added with $\mathrm{CHL}$ as sole carbon source was isolated from this soil. Although this strain was able to rapidly dissipate $\mathrm{CHL}$ in liquid culture, it was not able to mineralize ${ }^{14} \mathrm{C}-\mathrm{CHL}$ labelled on the pyrazine ring. In addition, S10 was shown to be a good biosorbent able to fully dissipate $\mathrm{CHL}$ within one day both in liquid medium and in soil microcosms. The present study offers new insight in the development of a remediation technology of $\mathrm{CHL}$ and other hydrophobic pollutants, based on the use of $\mathrm{S} 10$ as a biosorbent.

\section{Declarations}

\section{Acknowledgements}

The authors would like to thank the Tunisian Ministry of Higher Education and Scientific Research and University of Carthage for providing support for two training periods at the University of Cagliari (Cagliari, Italy). The authors would like to thank Nadine Rouard (AgroSup Dijon, Université de Bourgogne) for helpful contribution.

\section{Authors' contributions}

All authors contributed significantly to this work. Method and optimization, analysis, and data evaluation were performed by ABS, HC, PC, VC, FML and SF. PC and V.C conducted the analytical assays. MD and JB carried out the experiments of mineralization and $16 \mathrm{~S}$ rRNA sequencing. TG did the statistical analysis and the figures. The first draft of the manuscript was written by ABS and FML. All authors commented on previous versions of the manuscript. All authors read and approved the final submitted manuscript.

\section{Funding}


This work was in part financially supported by the collaborative project PHC-MAGHREB (32618SA, $\mathrm{CMCU}$ ), by Bayer CropScience and ANGed (National Agency of management of waste).

\section{Data availability}

The datasets from which the current study was created are available from the corresponding author on reasonable request.

\section{Conflict of interest}

The authors declare that they have no conflict of interest.

\section{Ethical approval}

Not applicable

\section{Consent to participate}

Not applicable

\section{Consent for publication}

The manuscript has been read and approved for submission by all the named authors

\section{References}

1. Abo-Amer AE (2011) Biodegradation of diazinon by Serratia marcescens DI 101 and its use in bioremediation of contaminated environment. J Microbiol Biotechnol 21:71-80

2. Abraham J, Shanker A, Silambarasan S (2013) Role of Gordonia sp JAAS1 in biodegradation of chlorpyrifos and its hydrolysing metabolite 3,5,6-trichloro-2-pyridinol. Lett Appl Microbiol 57:510-516

3. Abraham J, Silambarasan S (2016) Biodegradation of chlorpyrifos and its hydrolysis product 3,5,6trichloro-2-pyridinol using a novel bacterium Ochrobactrum sp. JAS2: A proposal of its metabolic pathway. Pest. Biochem. Physiol. 126, 13-21.

4. Angelova B, Schmauder HP (1999) Lipophilic compounds in biotechnology-interactions with cells and technological problems. J Biotech 67:13-32

5. Ayangbenro AS, Babalola 00 (2017) A new strategy for heaving metal polluted environments: a review of microbial biosorbents. Int J Environ Rea Pub Hea 14:94, 1-16 
6. Ben Salem A, Azzouzi S, Mougou A, Salghi R, Chaabane H, Fattouch S (2016) Biochemical characterization and bioremediation study of dimthoate and chlorpyrifos tolerant bacterial strains isolated from an agricultural soil. J New Sci 33:1901-1909

7. Benoit P, Barriuso E, Calvet R (1998) Biosorption characterization of herbicides, 2,4-D and atrazine, and two chlorophenols on fungal mycelium. Chemosphere 37:1271-1282

8. Chen SH, Hu MY, Liu JJ, Zhong GH, Yang. L (2011) Biodegradation of beta-cypermethrin and 3phenoxybenzoic acid by a novel Ochrobactrum lupine DG-S-01. J Haz Mat 187:433-440

9. Chisti Z, Hussain S, Arshad KR, Khalid A, Arshad M (2013) Microbial dissipation of chlorpyrifos in liquid media and soil. J Environ Manag 114:372-380

10. Copley SD (2009) Evolution of efficient pathways for degradation of anthropogenic chemicals. Nature Chem Biol 5:559-566

11. Crouzet O, Batisson I, Besse-Hoggan P, Bonnemoy F, Bardot C, Poly F, Bohatier J, Mallet C (2010) Response of soil microbial communities to the herbicide mesotrione: a dose-effect microcosmapproach. Soil Biol Biochem 42:193-202

12. Cycon M, Zmijowska A, Wójcik M, Piotrowska-Seget Z (2013) Biodegradation and bioremediation potential of diazinon-degrading Serratia marcescens to remove other organophosphorus pesticides from soils. J Environ Manag 117:7-16

13. De Andrea MM, Peres TB, Luchini LC, Bazarin S, Papini S, Matallo MB, Savoy T, V.L (2003) Influence of repeated applications of glyphosate on its persistence and soil bioactivity. Pes Agro Bras 38:1329-1335

14. Devers M, Rouard N, Martin-Laurent F (2008) Fitness drift of an atrazine-degrading population under atrazine selection pressure. Environ Microbiol 10:676-684

15. El-Sebai T, Lagacherie B, Soulas G, Martin-Laurent F (2007) Spatial variability of isoproturon mineralizing activity within an agricultural field: geostatistical analysis of simple physicochemical and microbiological soil parameters. Environ Pollut 145:680-690

16. Fang H, Yu YL, Chu XQ, Wang XG, Yang XE, Yu JQ (2009) Dissipation of chlorpyrifos in laboratory soil and its impact on soil microbial functional diversity. J Environ Sci 21:380-386

17. FOCUS (2006) Guidance document on estimating persistence and degradation kinetics from environmental fate studies on pesticides in EU registration. Report of the FOCUS Work Group on Degradation Kinetics, EC Document Reference Sanco/10058/ 2005 version 2.0, 2006 (434 pp.)

18. Ghanem I, Orfi M, Shamma M (2007) Biodegradation of Chlorpyrifos by Klebsiella sp. isolated from an activated sludge sample of waste water treatment plant in Damascus. Folia Microbiol 52:423427

19. Gurtler V, Stanisich VA (1996) New approaches to typing and identification of bacteria using the 16S-23S rDNA spacer region. Microbiology 142:3-16

20. Hussain S, Devers-Lamrani M, Azhari E, Martin-Laurent N, F (2011) Isolation and characterization of an isoproturon mineralizing Sphingomonas sp. strain $\mathrm{SH}$ from a French agricultural soil. Biodegradation 22:637-650 
21. Ishag AESA, Abdelbagi AO, Hammad AMA, Elsheikh EAE, Elsaid OE, Hur J-H, Laing MD (2016) Biodegradation of Chlorpyrifos, Malathion, and Dimethoate by Three Strains of Bacteria Isolated from Pesticide-Polluted Soils in Sudan. J Agric Food Chem 64:8491-8498

22. Iyer P, Makris S (2010) Developmental and Reproductive Toxicology of Pesticides. Hayes' Handbook of Pesticide Toxicology, 381-440

23. Khadivinia E, Sharafi H, Hadi F, Zahiri HS, Modiri S, Tohidi A, Mousavi A, Salmanian AH (2014) Cadmium biosorption by a glyphosate-degrading bacterium, a novel biosorbent isolated from pesticide-contaminated agricultural soils. J Ind Eng Chem 20:4304-4310

24. Khalid S, Hashmi I, Khan Sher J (2016) Bacterial assisted degradation of chlorpyrifos: The key role of environmental conditions, trace metals and organic solvents. J Environ Manag 168:1-9

25. Krieg NR, Holt JG (1984) Bergey's manual of systematic bacteriology. Willliams and Wilkins, Baltimore

26. Lakshmi CV, Kumar M, Khanna S (2008) Biotransformation of Chlorpyrifos and Bioremediation of contaminated soil. Inter Biodeter Biodegrad 62:204-209

27. Lakshmi C, Kumar V, Khanna M, S (2009) Biodegradation of chlorpyrifos in soil by enriched cultures. Curr Microbiol 58:35-38

28. Liang B, Yang CH, Gong M, Zhao Y, Zhang J, Zhu C, Jiang J, Li S (2011) Adsorption and degradation of triazophos, chlorpyriphos and their main hydrolytic metabolites in paddy soil from Chaohu Lake, China. J Environ Manag 92:2229-2234

29. Li X, Jiang J, Gu L, Shinwar WA, Jian H, Li S (2008) Diversity of chlorpyrifos-degrading bacteria isolated from chlorpyrifos-contaminated samples. Inter Biodeter Biodegrad 62:331-335

30. Li Y, Ching-Hong Yu-hua,ZBing-xin,Zhang, Xin Y, Zhang (2005) Isolation and characterization of a chlorpyrifos and 3,5,6-trichloro-2-pyridinol degrading bacterium. FEMS Microbiol Lett 251:67-73

31. Li X, He J, Li S (2007) Isolation of chlorpyrifos degrading bacterium, Sphingomonas sp. strain Dsp-2, and cloning of the $m p d$ gene. Res Microbiol 158:143-149

32. Lu P, Li Q, Liu H, Zhaozhong F,. Xin, Y.,. Qing H, Shunpeng L (2013) Biodegradation of chlorpyrifos and 3,5,6-trichloro-2-pyridinol by Cupriavidus sp. DT-1. Biores Technol 127, 337-342

33. Lui Z, Chen X, Shi Y, Su Z (2012) Bacterial degradation of chlorpyrifos by Bacillus cereus. Adv Mater Resous 356-360:676-680

34. Mallick BK, Banerji A, Shakli NA, Sethunathan NN (1999) Bacterial degradation of chlorpyrifos in pure culture and in soil. Bull Environ Contam Toxicol 62:48-55

35. Martin AR, Calva GC, Avelizapa NR, Diaz-Cervantes MD, Vazquez RR (2007) Solid culture amended with small amounts of raw coffee beans for the removal of petroleum hydrocarbon from weathered contamination soil. Int Biodeterior Biodegrad 60:35-39

36. Merlin C, Devers M, Crouzet O, Heraud C, Steinberg C, Mougin C, Martin-Laurent F (2014) Characterization of chlordecone-tolerant fungal populations isolated from long-term polluted tropical volcanic soil in the French West Indies". Environ Sci Pollut Res 21:4914-4927 
37. Mosa KA, Saadoun I, Kumar K, Helmy M, Dhankher OP (2016) Potential biotechnological strategies for the cleanup of heavy metals and metalloids. Front Plant Sci 7:1-14

38. Pathak RK, Dikshit AK (2011) Isolation and characterization of bacterial strains to be used as biosorbent for removal of atrazine from wastewater. 2nd International Conference on Environmental Science and Technology IPCBEE vol.6 IACSIT Press, Singapore

39. Pino N, Penuela G (2011) Simultaneous degradation of the pesticides methylparathion and chlorpyrifos by an isolate bacterial consortium from a contaminated site. Int Biodeterior Biodegrad 65:827-831

40. Sikkema J, Weber FJ, Heipieper H-J, De Bont JAM (1994a) Cellular toxicity of lipophilic compounds: mechanisms, implication and adaptations. Biocatalysis 10:113-212

41. Sikkema J, Weber FJ, De Bont JAM, Poolman B (1994b) Interactions of cyclic hydrocarbons with biological membranes. J Biol Chem 269:8022-8028

42. Sikkema J, Weber FJ, De Bont JAM, Poolman B (1995) Mechanisms of membrane toxicity of hydrocarbons. Microbiol Rev 59:201-222

43. Silambarasan, S., and Abraham, J. (2013). Kinetic studies on enhancement of degradation of chlorpyrifos and its hydrolyzing metabolite TCP by a newly isolated Alcaligenes sp. JAS1. J. Taiwan Inst. Chem. Engin. 44, 438-445.

44. Singh BK, Walker A, Morgan JAW, Wright DJ (2003) Effects of soil pH on the biodegradation of chlorpyrifos and isolation of a chlorpyrifos-degrading bacterium. Appl Environ Microbiol 69:51985206

45. Singh BK, Walker A (2006) Microbial degradation of organophosphorous compounds. FEMS Microbiol Rev 30:428-471

46. Singh BK, Walker A, Wright DJ (2006) Bioremedial potential of fenamiphos and chlorpyrifos degrading isolates: influence of different environmental conditions. Soil Biol Biochem 38:2682-2693

47. Singh B (2009) Organophosphorus-degrading bacteria: ecology and industrial applications. Nat Rev Microbiol 7:156-164

48. Storck V, Karpouzas DG, Martin-Laurent F (2017) Towards a better pesticide policy for the European Union. Sci Tot Environ 575:1027-1033

49. Topp E, Martin-Laurent F, Hartmann A, Soulas G (2004) Bioremediation of atrazine-contamined soil, 141-154. In: Gan JJ, Zhu PC, Aust SD, Lemley AT (eds) "Pesticide, Decontamination and Detoxification". American Chemical Society, Washington, DC, $266 \mathrm{p}$

50. Vischetti C, Monaci E, Cardinali A, Casucci C, Perucci P (2008) The effect of initial concentration, coapplication and repeated applications on pesticide degradation in a biobed mixture. Chem 72:17391743

51. Weaver MA, Krutz LJ, Zablotowicz RM, Reddy KN (2007) Effects of glyphosate on soil microbial communities and its Mississippi soil. Pest Manag Sci 63:388-393 
52. Weber FJ, De Bont JAM (1996) Adaptation mechanisms of microorganisms to the toxic effect of organic solvents on membranes. Biochem Biophys Acta 1286:225-245

53. Xu G, Li. Y, Zheng W, Xiang P, Li W, Yan Y (2007) Mineralization of chlorpyrifos by co-culture of Serratia and Trichosporon spp. Biotechnol Lett 29:1469-1473

54. Xu G, Zheng W, Li. Y, Wang. S, Zhang. J, Yan. Y (2008) Biodegradation of chlorpyrifos and 3,5,6trichloro-2-pyridinol by a newly isolated Paracoccus sp. strain TRP. Int Biodeter Biodegr 62:51-56

55. Yang $L$, Zhao $Y$, Zhang $B$, Yang $C H$, Zhang $X$ (2005) Isolation and characterization of a chlorpyrifos and 3, 5, 6-trichloro-2-pyridinol degrading bacterium. FEMS Microbiol Lett 251:67-73

56. Yang C, Liu N, Guo X, Qiao C (2006) Cloning of $m p d$ gene from a chlorpyrifos-degrading bacterium and use of this strain in bioremediation of contaminated soil. FEMS. Microbiol Lett 265:118-125

57. Zakeri F, Noghabi KA, Sadeghizadeh M, Kardan MR, Massomi F, Farshidpour MR, Atarilar A (2010) Serratia sp. ZF03: an efficient radium biosorbent isolated from hot-spring waters in high backround radiation areas. Bioresour Technol 101:9163-9170

\section{Figures}

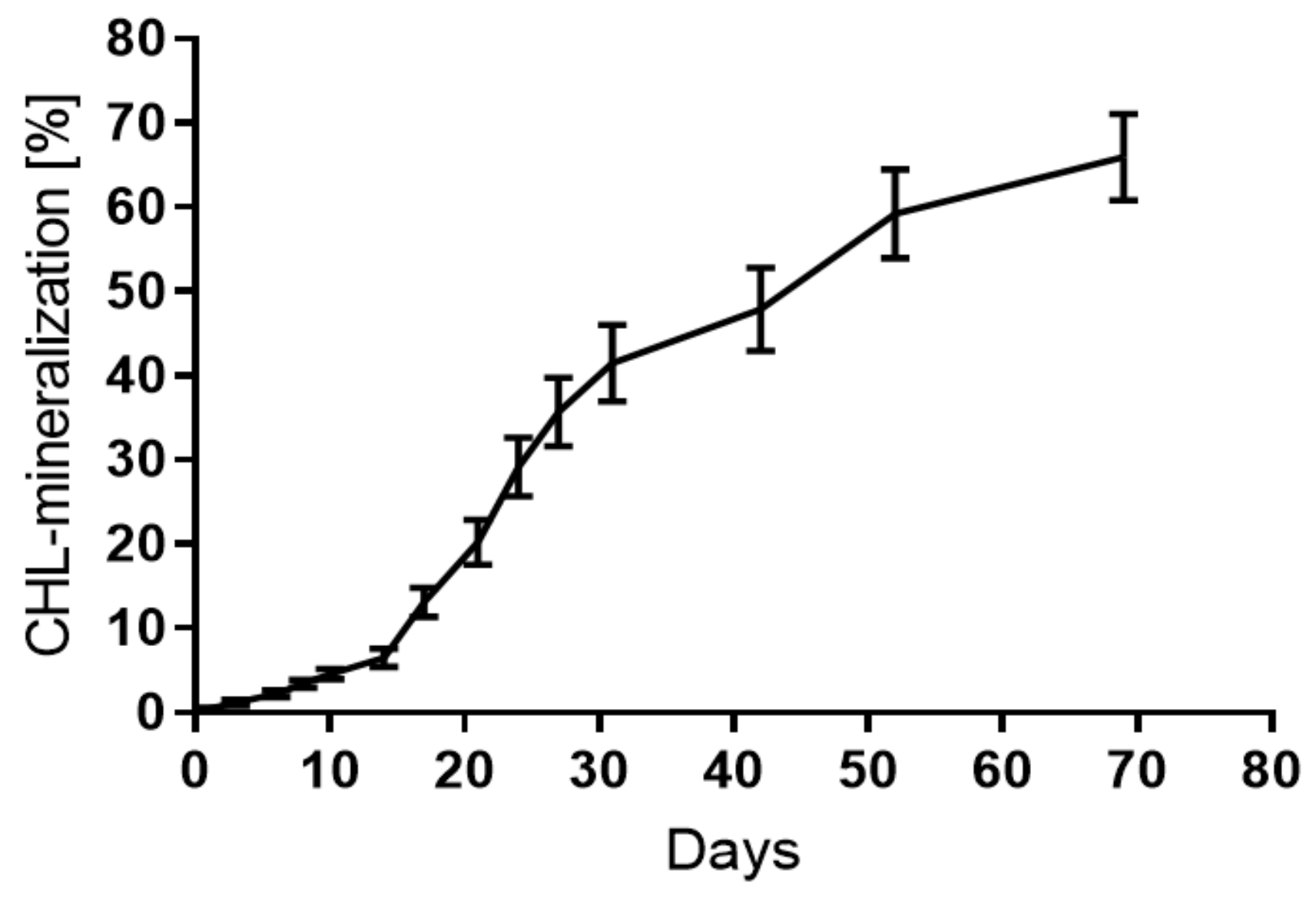

Figure 1 
Kinetics of mineralization of $14 \mathrm{C}$-chlorpyrifos $(\mathrm{CHL})$ in the soil over an eighty days incubation period. Mean values \pm standard deviation of percentage of initially added $14 \mathrm{C}-\mathrm{CHLare}$ shown $(n=3)$
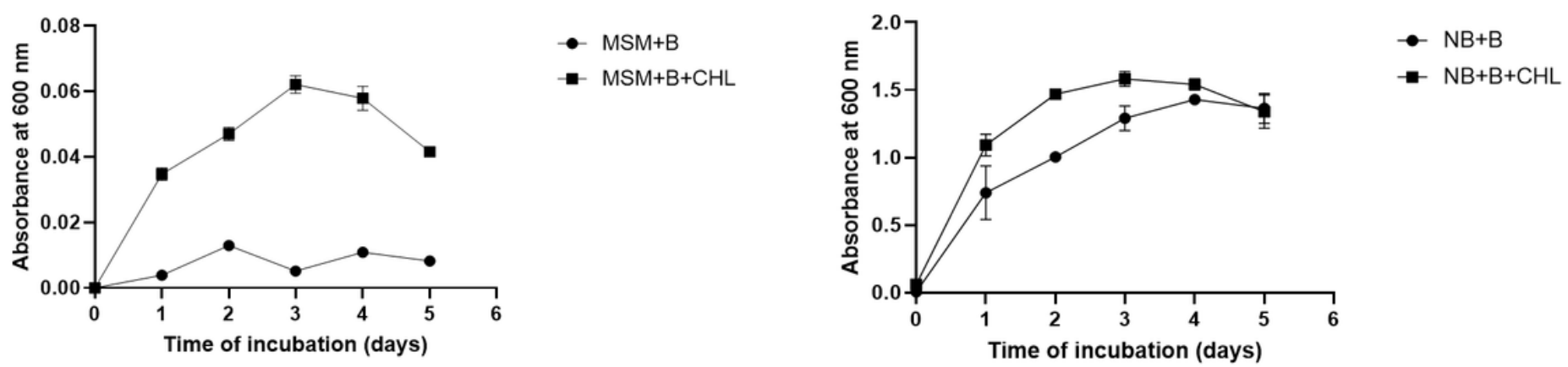

Figure 2

Growth of Serratia rubidaea strain ABS 10 (B) in mineral salt medium (MSM) and nutrient broth (NB) liquid media supplemented with chlorpyriphos $(\mathrm{CHL})$ or not. Mean values (arbitrary unit, a. u., absorbance at $600 \mathrm{~nm}) \pm$ standard deviation are shown ( $\mathrm{n}=3$ per treatment).

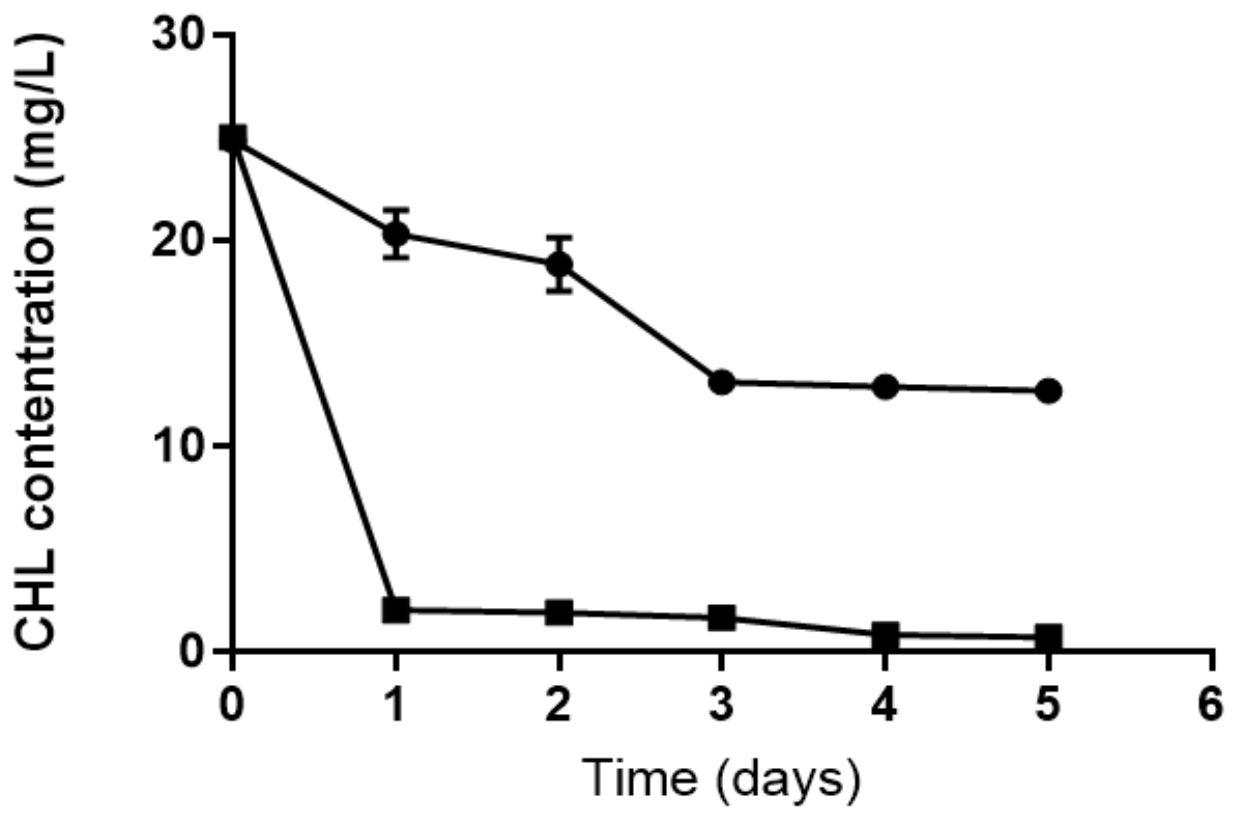

$\leadsto \mathrm{MSM}+\mathrm{CHL}$

$\rightarrow \mathrm{MSM}+\mathrm{B}+\mathrm{CHL}$

Figure 3

Dissipation of chlorpyrifos (CHL) in Serratia rubidaea strain ABS 10culture (B) and in mineral salt (MSM). Mean values \pm standard deviation are shown ( $n=3$ per treatment). 


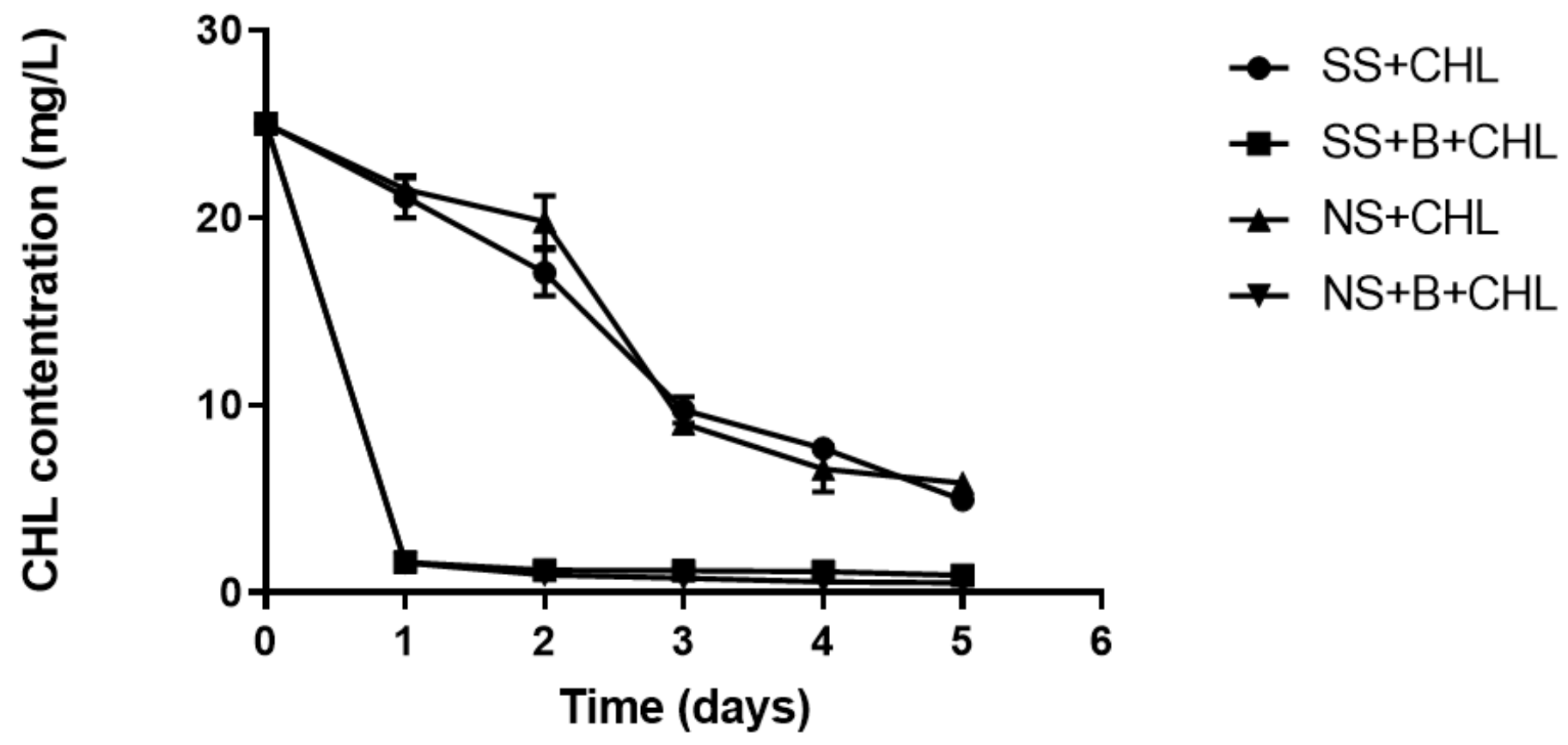

Figure 4

Dissipation of chlorpyrifos (CHL) in sterile (SS) or native (NS) soil inoculated with Serratia rubidaea strain ABS 10 (B) of not. Mean values \pm standard deviation are shown ( $n=3$ per treatment). 